\title{
The optimal control system of the ship based on the linear quadratic regular algorithm
}

\author{
Manh-Cuong Nguyen ${ }^{1}$, Duc-Phuc Vuong ${ }^{2}$ \\ ${ }^{1}$ Faculty of Navigation, Vietnam Maritime University, Vietnam \\ ${ }^{2}$ Faculty of Electrical and Electronic Engineering, Vietnam Maritime University, Vietnam
}

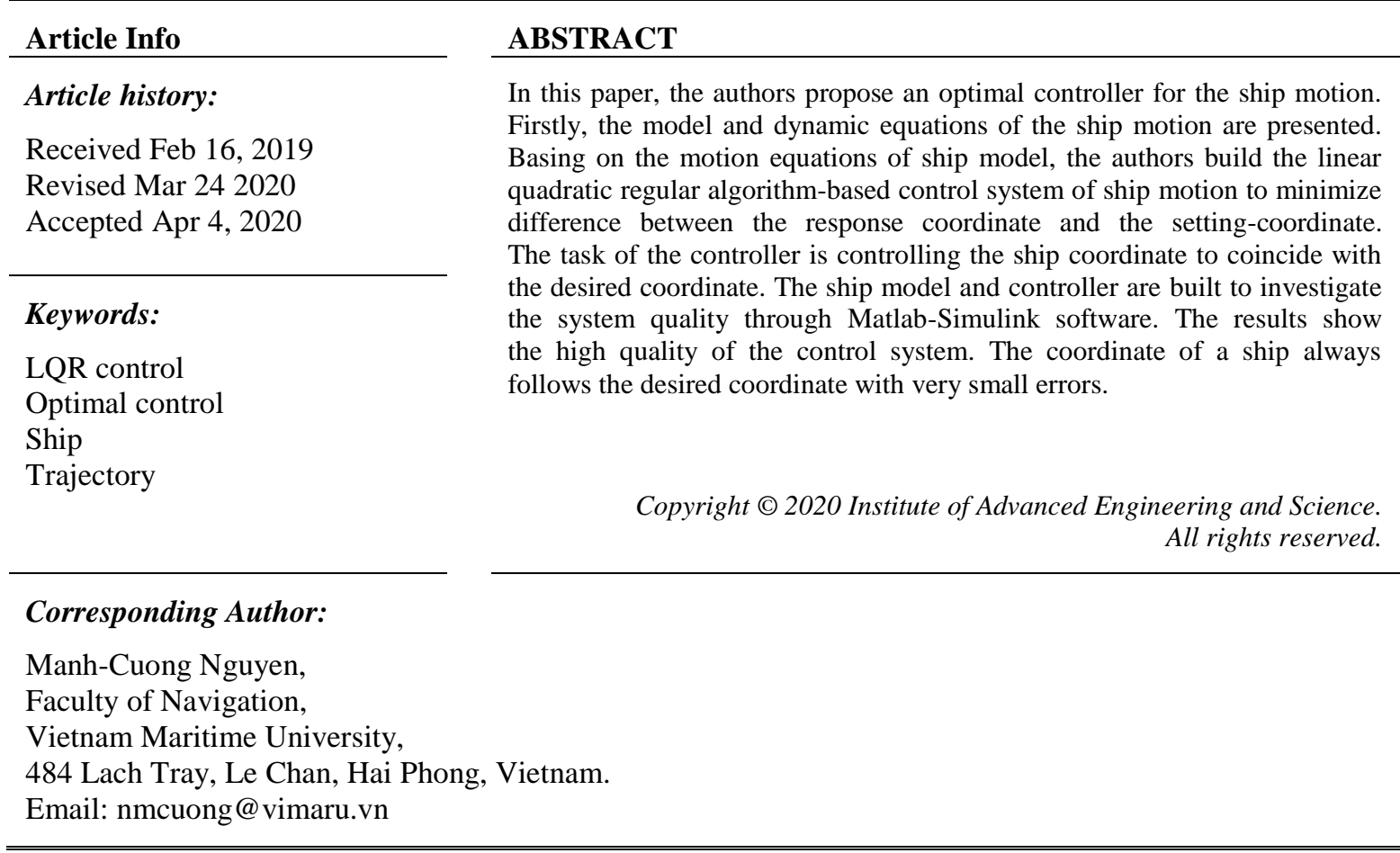

\section{INTRODUCTION}

Transport by ship has outstanding advantages such as low shipping cost, high carrying capacity, wide transport range, etc. Maritime transport plays an increasingly important role, it accounts for $80 \%$ of all goods shipped worldwide. Therefore, it is very important to improve the maritime safety the transport efficiency by ship. However, the equation of ship model is a complex so it is difficult to control the ship motion with a high-quality. The order of ship motion differential equation is high. The ship-dynamic characteristics have properties such as the large time constant, the high-vibration and the small stabilization margin [1]. Thus, the ship motion control has been a challenge of researchers.

The traditional controller commonly used in ship motion control is the proportional integral derivative (PID) controller [2-4]. This is a controller with a simple structure, but the quality of the control system is not high. Recently, the development of informatics and electronic technology let the scientist to set up the advanced control theory for ship, such as fuzzy control [5-7], the model predictive control [8-10], the sliding mode control [11, 12], the backstepping technique [13, 14], the adaptive control [15, 16], etc. The research [17] has proposed the control system of the ship in order for the motion trajectory to follow with the desired trajectory based on the backstepping technique. However, the trajectory is only straight and the speed is only positive and constant. To overcome the above disadvantage, the research [18] has built the controller of trajectory ship based on the backstepping technique and Lyapunov function. The research [19] has provided a linear-algebra controller that is built by linearizing of nonlinear model.

The disadvantage of the above-mentioned control methods are the complex process of calculating, the complex control algorithms, high harmonic of control signals, causing the lifespan of the actuator and equipment reduces. To overcome all the limitations of the previous method, in this study, the authors propose 
a solution to build a control system based on the linear quadratic regulator (LQR) controller [20-22]. The control algorithm is simple and the quality is high [23], the trajectory of a ship always follows the desired trajectory with very small errors.

The remains of the paper are as follows: Section 2 presents the model equations of ship motion. The Section 3 presents linear quadratic regular algorithm-based controller for ship motion. Section 4 presents the results and analysis. Finally, the conclusions are presented in section 5.

\section{THE MODEL OF SHIP}

The ship moving components on the sea surface are shown in Figure 1. Those components are the rotary motion $(r)$, the straight slide motion $(u)$ and horizontal slide motion $(v)$. The ignored components are the yaw rotary motion $(\omega=0)$, roll rotary motion $(p=0)$ and pitch rotary motion $(q=0)$.

In the three-degrees-of-freedom space, the ship motion is described through the position vector $\underline{\eta}=[x, y, z]^{T}$ and the speed vector $\underline{v}=[u, v, r]^{T}$. Where: $u, v, r$ are the speed of straight slide, the speed of horizontal slide and the speed of rotation, respectively.

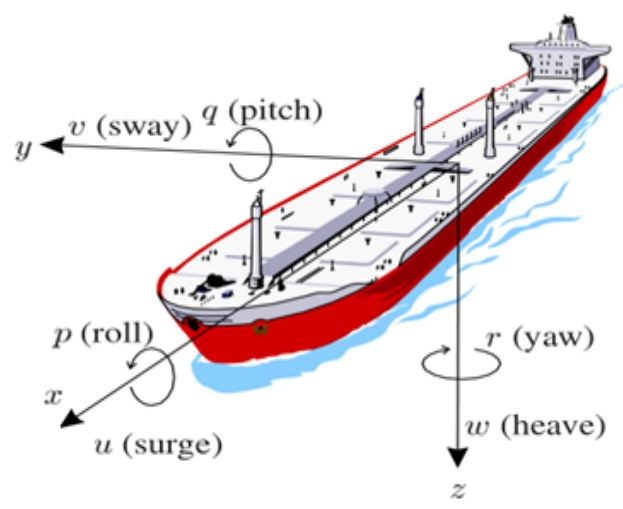

a)

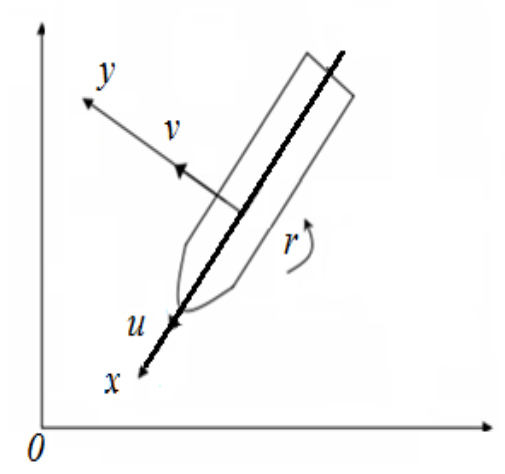

b)

Figure 1. The ship moving components

Because of the disturbances force from the environment is very small compared with the force of actuators, on the three-degree-freedom coordinate, the ship motion equations are as follows [24, 25]:

where: $\left\{\begin{array}{c}\dot{\dot{\eta}}=J(\underline{\eta}) \underline{v} \\ M \underline{\dot{v}}+C(\underline{v}) \underline{v}+D(\underline{v}) \underline{v}+g(\underline{\eta})=\underline{\tau}\end{array}\right.$

Mrepresents the inertial matrix:

$$
M=\left[\begin{array}{ccc}
m_{11} & 0 & 0 \\
0 & m_{22} & 0 \\
0 & 0 & m_{33}
\end{array}\right]
$$

$C(\underline{v})$ represents the centrifugal and Coriolis forces:

$$
C(\underline{v})=\left[\begin{array}{ccc}
0 & 0 & -m_{22} v \\
0 & 0 & m_{11} u \\
m_{22} v & -m_{11} u & 0
\end{array}\right]
$$

$D(\underline{v})$ represents the hydrodynamic damping matrix:

$$
D(\underline{v})=\left[\begin{array}{ccc}
d_{11} & 0 & 0 \\
0 & d_{22} & 0 \\
0 & 0 & d_{33}
\end{array}\right]
$$


$J(\underline{\eta})$ represents the orthogonal matrix:

$$
J(\underline{\eta})=\left[\begin{array}{ccc}
\cos \psi & -\sin \psi & 0 \\
\sin \psi & \cos \psi & 0 \\
0 & 0 & 1
\end{array}\right]
$$

$g(\underline{\eta})$ denotes the gravity forces; $\underline{\tau}$ is the vector of control torques, including the propeller force and the rudder force.

In the mathematical model (1), the ship is called a fully-actuated ship if there are all force components $\left(\tau_{u}, \tau_{v}, \tau_{r}\right)$. This kind of ship has full actuators. The straight-slide force is controlled by the main propeller, the horizontal slide force is controlled by the horizontal propeller on both sides, and the ship direction is controlled by the rudder. This kind is usually applied to the ship for marine-researching, specialtask and serving.

If there is no horizontal slide force means that $\tau_{v}=0$, it is named underactuated ship. There are only two actuators in this ship: the rudder for controlling the direction and the main propeller for controlling the straight-force. This kind is usually applied to the ships for the long transport journey, container and cargo.

In this paper, the authors perform the control of a fully-actuated ship. Considering (1), setting: $\underline{x}_{1}=\underline{\eta}, \underline{x}_{2}=\underline{v}, \underline{u}=\underline{\tau}$, and $\underline{x}=\operatorname{col}\left(\underline{x}_{1}, \underline{x}_{2}\right)$. We thus have the following:

$$
\left(\begin{array}{l}
\dot{\dot{\eta}} \\
\dot{\dot{v}}
\end{array}\right)=\left(\begin{array}{cc}
0_{3 \times 3} & J(\underline{\eta}) \\
-G(\underline{\eta}) & -M^{-1}[C(\underline{v})+D(\underline{v})]
\end{array}\right)\left(\begin{array}{l}
\underline{\eta} \\
\underline{v}
\end{array}\right)+\left(\begin{array}{c}
0_{3 \times 3} \\
M^{-1}
\end{array}\right) \underline{\tau}
$$

Then: $\quad \underline{\dot{x}}=A(\underline{x}) \underline{x}+B \underline{u}$

where:

$$
A(\underline{x})=\left(\begin{array}{cc}
0_{3 \times 3} & J\left(\underline{x}_{1}\right) \\
-G\left(\underline{x_{1}}\right) & -M^{-1}\left[C\left(\underline{x}_{2}\right)+D\left(\underline{x}_{2}\right)\right]
\end{array}\right) \quad B=\left(\begin{array}{l}
0_{3 \times 3} \\
M^{-1}
\end{array}\right)
$$

The (3) is the state equation of the ship.

\section{THE LQR CONTROLLER FOR SHIP MOTION}

The state equation of ship are as following:

$\underline{\dot{x}}(t)=A \cdot \underline{x}(t)+B \cdot \underline{u}(t)$

where: $\underline{x}(t)=[x, y, \psi, u, v, r]^{T}$ is the vector of state signal.

$u(t)=\underline{\tau}=\left[\tau_{u}, \tau_{v}, \tau_{r}\right]^{T}$ is the vector of control signal.

We must design the control signal $u(t)$ in order for $\lim _{t \rightarrow \infty}\left(\underline{x}_{\text {response }}-\underline{x}_{\text {set }}\right) \rightarrow 0$.

where: $\underline{x}_{\text {response }}$ is the state vector of response signal

$\underline{x}_{\text {set }}$ is the state vector of desired signal.

Named $\underline{x}_{e}$ is the error between $\underline{x}_{\text {response }}$ and $\underline{x}_{\text {set }}$.

The state (4) is rewritten as follows:

$\underline{\dot{x}}_{e}(t)=A \cdot \underline{x}_{e}(t)+B \cdot \underline{u}(t)$

where:

$$
A(\underline{x})=\left(\begin{array}{cc}
0_{3 \times 3} & J\left(\underline{x}_{1}\right) \\
-G\left(\underline{x}_{1}\right) & -M^{-1}\left[C\left(\underline{x}_{2}\right)+D\left(\underline{x}_{2}\right)\right]
\end{array}\right) \quad B=\left(\begin{array}{l}
0_{3 \times 3} \\
M^{-1}
\end{array}\right)
$$

The requirement of the control system is to find the control signal $u(t)=\underline{\tau}=\left[\begin{array}{l}\tau_{u} \\ \tau_{v} \\ \tau_{r}\end{array}\right]$ in order for the control object from the initial state $\underline{x}_{e}\left(t_{0}\right)=\underline{x}_{e}(0)$ go to the end state $\underline{x}_{e}\left(t_{f}\right)=0$ and satisfy the following condition: 


$$
J=\frac{1}{2} \underline{x}_{e}^{T}\left(t_{f}\right) \cdot M \cdot \underline{x}_{e}\left(t_{f}\right)+\frac{1}{2} \int_{t_{0}}^{t_{f} \int}\left[\underline{x}_{e}^{T}(t) \cdot Q \cdot \underline{x}_{e}(t)+\underline{u}^{T}(t) \cdot R \cdot \underline{u}(t)\right] d t \rightarrow \min
$$

where $Q$ and $\mathrm{M}$ are the symmetric, positive semi-definite weight matrix. $R$ is the symmetric, positive definite weight matrix. Jis called cost functional.

To solve the problem, we set the Hamilton function:

$$
H=\frac{1}{2}\left[\underline{x}_{e}^{T}(t) \cdot Q \cdot \underline{x}_{e}(t)+\underline{u}^{T}(t) \cdot R \cdot \underline{u}(t)\right]+\lambda^{T}[A \cdot \underline{x}(t)+B \cdot \underline{u}(t)]
$$

The optimal experiment is the solution of the following equations:

The state equation:

$$
\underline{\dot{x}}_{e}(t)=A \cdot \underline{x}_{e}(t)+B \cdot \underline{u}(t)
$$

The equilibrium equation:

$$
\dot{\lambda}(t)=-\frac{\partial H}{\partial \underline{x}_{e}}=-Q \cdot \underline{x}_{e}(t)-A \cdot \lambda^{T}(t)
$$

The optimal condition:

$$
\frac{\partial H}{\partial \underline{u}}=R \cdot \underline{u}(t)+B^{T} \cdot \lambda^{T}(t)=0
$$

From (10), we have:

$$
\underline{u}(t)=-R^{-1} \cdot B^{T} \cdot \lambda^{T}(t)
$$

Replace $\underline{u}(t)$ into (8), we have:

$$
\underline{\dot{x}}_{e}(t)=A \cdot \underline{x}_{e}(t)-B \cdot R^{-1} \cdot B^{T} \cdot \lambda^{T}(t)
$$

Combining (12) and (9) we have:

$$
\left[\begin{array}{c}
\dot{x}(t) \\
\dot{\lambda}(t)
\end{array}\right]=\left[\begin{array}{cc}
A & -B \cdot R^{-1} \cdot B^{T} \\
-Q & -A
\end{array}\right]\left[\begin{array}{c}
x(t) \\
\lambda^{T}(t)
\end{array}\right]
$$

Solving the above equations, we have the optimal control signal:

$$
u^{*}(t)=-K(t) \cdot \underline{x}_{e}(t)
$$

where $K(t)=R^{-1} \cdot B^{T} \cdot P(t)$

$P(t)$ is the positive semi-definite solution of the Riccati equation:

$$
-\dot{P}=P \cdot A+A^{T} \cdot P+Q-P \cdot B \cdot R^{-1} \cdot B^{T} \cdot P
$$

Because of the infinite time $t_{f}=\infty$, the cost function is as follows:

$$
J=\frac{1}{2} \int_{0}^{t_{f} \int}\left[\underline{x}_{e}^{T}(t) \cdot Q \cdot \underline{x}_{e}(t)+\underline{u}^{T}(t) \cdot R \cdot \underline{u}(t)\right] d t \rightarrow \min
$$

The optimal control signal:

$$
u^{*}(t)=-K \cdot \underline{x_{e}}(t)
$$

where $K=R^{-1} \cdot B^{T} . P$

$P$ is the positive semi-definite solution of the Riccati equation:

$$
P \cdot A+A^{T} \cdot P+Q-P \cdot B \cdot R^{-1} \cdot B^{T} \cdot P=0
$$


( $K$ and $P$ are independence to the time). In conclusion, if we set the control signalu $(t)=-K \cdot \underline{x_{e}}(t)$, the signals in the state vector will follow the desired values with the smallest error.

\section{RESULTS AND DISCUSSIONS}

The authors built the optimal LQR control system for ships on Matlab-Simulink software. The block diagram of the control system is shown in Figure 2. The parameters of the ship are shown in Table 1.

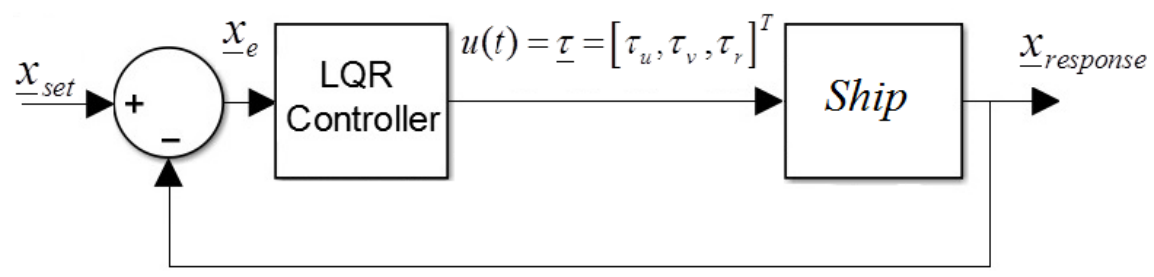

Figure 2. The control system diagram

Table 1. The parameters of ship

\begin{tabular}{llllll}
\hline $\mathrm{m}_{11}(\mathrm{~kg})$ & $\mathrm{m}_{22}(\mathrm{~kg})$ & $\mathrm{m}_{33}(\mathrm{~kg})$ & $\mathrm{d}_{11}(\mathrm{~kg} / \mathrm{s})$ & $\mathrm{d}_{22}(\mathrm{~kg} / \mathrm{s})$ & $\left.\mathrm{d}_{33}(\mathrm{~kg} / \mathrm{s})\right)$ \\
\hline $95.10^{3}$ & $135.10^{3}$ & $542.10^{5}$ & $197.10^{2}$ & $152.10^{3}$ & $779.10^{4}$ \\
\hline
\end{tabular}

The quality of control system and the goal depend on the matrices $Q, R$. The authors set the optimal controller with the weight matrices are as follows:

$$
Q=\left[\begin{array}{llllll}
20 & 0 & 0 & 0 & 0 & 0 \\
0 & 30 & 0 & 0 & 0 & 0 \\
0 & 0 & 0 & 0 & 0 & 0 \\
0 & 0 & 0 & 10 & 0 & 0 \\
0 & 0 & 0 & 0 & 10 & 0 \\
0 & 0 & 0 & 0 & 0 & 5
\end{array}\right] ; R=\left[\begin{array}{ccc}
3 & 0 & 0 \\
0 & 0.5 & 0 \\
0 & 0 & 3
\end{array}\right]
$$

Running the entire control system, we have the results presented in Figure 3 and Figure 4. Figure 3 shows the ability to follow the desired trajectory of the ship. The simulation results show that the trajectory of the ship always follows the desired trajectory very well: the motion trajectory of the ship almost coincides with the desired trajectory. The trajectory errors of the ship motion in the $x, y$ directions are shown in Figure 4 . The results show that the orbit error in each direction is very small, less than $0.5 \mathrm{~m}$.

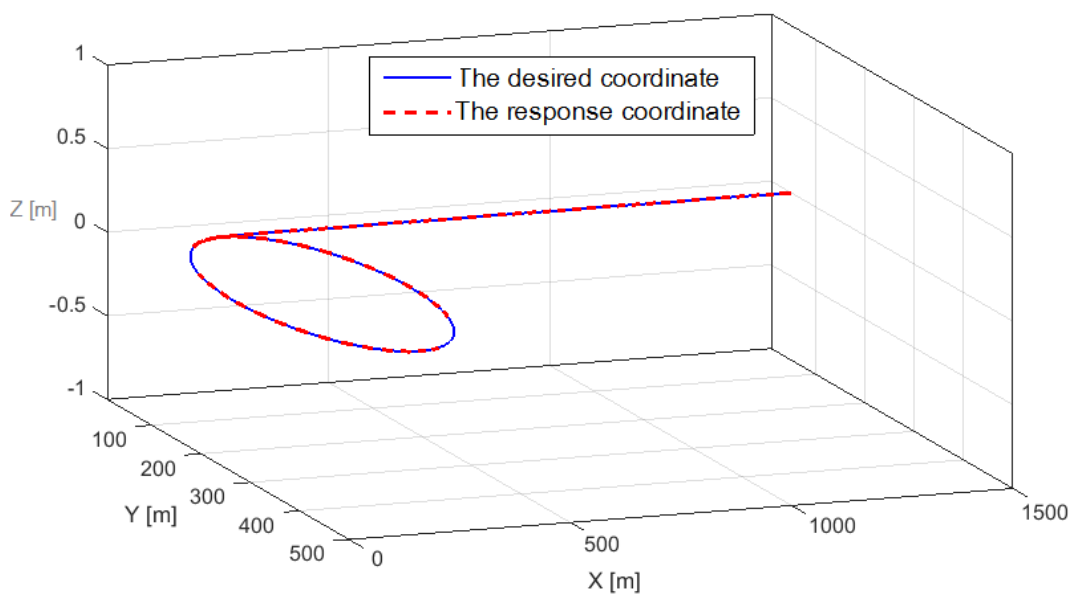

Figure 3. The ship movement trajectory 


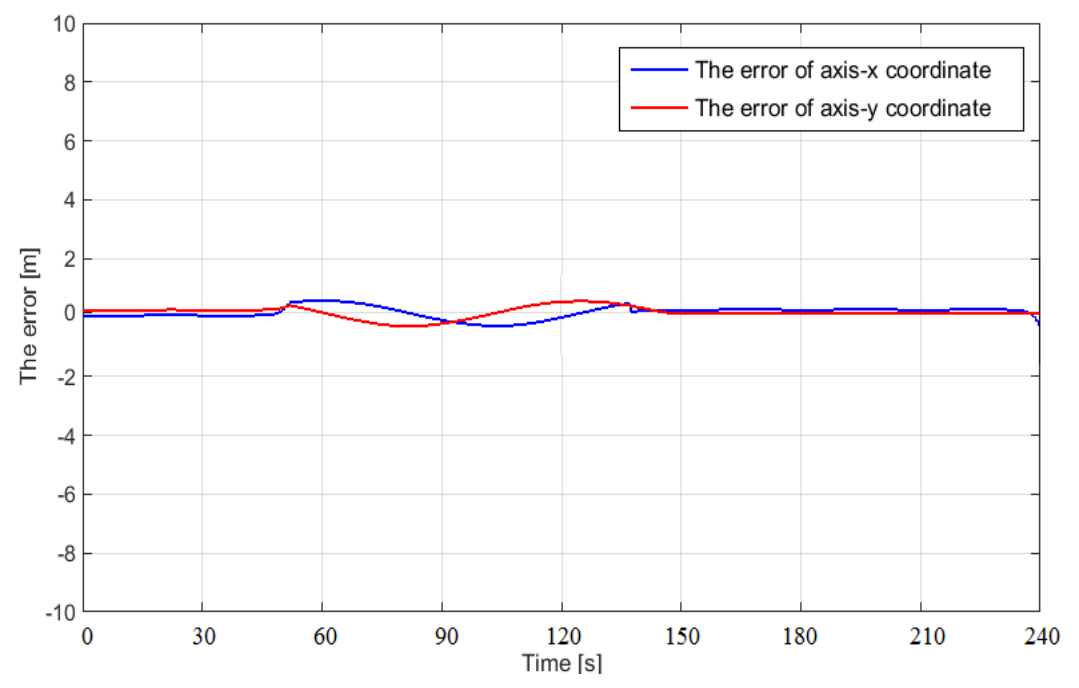

Figure 4. The errors of trajectory control

\section{CONCLUSION}

In this study, the author has succeeded in building the optimal controller LQR for the ship motion. The authors presented the dynamics equation of ship motion as a basis for setting up the algorithm of the optimal controller for the trajectory control. The simulation results show that although the algorithm of the proposed controller is very simple, the quality of the control system is very high. This is a good basis for applying the control algorithm to ship motion for improving the maritime safety and transport efficiency.

\section{REFERENCES}

[1] Fossen, T. I., "Marine Control Systems-Guidance. Navigation, and Control of Ships, Rigs and Underwater Vehicles," Marine Cybernetics, Trondheim, Norway, Org. Number NO 985195005 MVA, 2002.

[2] Le, M. D., Nguyen, S. H., and Nguyen, L. A., "Study on a new and effective fuzzy PID ship autopilot," Artificial life and robotics, vol. 8, no. 2, pp. 197-201, 2004.

[3] Knospe, C., "PID control," IEEE Control Systems Magazine, vol. 26, no. 1, pp. 30-31, 2006.

[4] O'Dwyer, A., "Handbook of PI and PID controller tuning rules," World Scientific, 2006.

[5] W. E. Ngongi, J. Du, and R. Wang, "Robust fuzzy controller design for dynamic positioning system of ships," International Journal of Control Automation \& Systems, vol. 14, no. 1, pp. 1-26, 2015.

[6] Ying, H., "Fuzzy control and modeling: analytical foundations and applications," Wiley-IEEE Press, 2000.

[7] Sugeno, M. A., and Nishida, M., "Fuzzy control of model car," Fuzzy sets and systems, vol. 16, no. 2, pp. 103-113, 1985.

[8] Nguyen, H. Q., Tran, A. D., Nguyen, T. T., "The Bilinear Model Predictive Method-Based Motion Control System of an Underactuated Ship with an Uncertain Model in the Disturbance," Processes, vol. 7, no. 7, p. 445, 2019.

[9] Camponogara, E., Jia, D., Krogh, B. H., and Talukdar, S., "Distributed model predictive control," IEEE control systems magazine, vol. 22, no. 1, pp. 44-52, 2002.

[10] Camacho, E. F., and Alba, C. B., "Model predictive control," Springer Science \& Business Media, 2013.

[11] Nguyen, T. T., "Sliding mode control-based system for the two-link robot arm," International Journal of Electrical and Computer Engineering (IJECE), vol. 9, no. 4, pp. 2088-8708, 2019.

[12] Song, J., Niu, Y., and Zou, Y., "Finite-time stabilization via sliding mode control," IEEE Transactions on Automatic Control, vol. 62, no. 3, pp. 1478-1483, 2016.

[13] A. Bateman, J. Hull, and Z. Lin, "A backstepping-based low-andhigh gain design for marine vehicles," International Journal of Robust \& Nonlinear Control, vol. 19, no. 4, pp. 480-493, 2009.

[14] Yu, J., Shi, P., and Zhao, L., "Finite-time command filtered backstepping control for a class of nonlinear systems," Automatica, vol. 92, pp. 173-180, 2018.

[15] Tran Anh, D., and Nguyen Trong, T., "Adaptive Controller of the Major Functions for Controlling a Drive System with Elastic Couplings," Energies, vol. 11, no. 3, p. 531, 2018.

[16] Liu, Y. J., and Tong, S., "Barrier Lyapunov functions for Nussbaum gain adaptive control of full state constrained nonlinear systems," Automatica, vol. 76, pp. 143-152, 2017.

[17] Do, K. D., Jiang, Z. P., and Pan, J., "Underactuated ship global tracking under relaxed conditions," IEEE Transactions on Automatic Control, vol. 47, no. 9, pp. 1529-1536, 2002.

[18] Godhavn, J. M., "Nonlinear tracking of underactuated surface vessels," In Proceedings of 35th IEEE Conference on Decision and Control, IEEE, vol. 1, pp. 975-980, 1996.

[19] Serrano, M. E., Scaglia, G. J., et al, "Tracking trajectory of underactuated surface vessels: a numerical method approach," Control Engineering and Applied Informatics, vol. 15, no.4, pp. 15-25, 2013.

The optimal control system of the ship based on the linear quadratic regular ... (Manh-Cuong Nguyen) 
[20] Bemporad, A., Morari, M., Dua, V., and Pistikopoulos, E. N., "The explicit linear quadratic regulator for constrained systems," Automatica, vol. 38, no. 1, pp. 3-20, 2002.

[21] Levine, W. S., "Linear quadratic regulator control," In the Control Systems Handbook, pp. 403-426, 2018.

[22] Dean, S., Mania, H., Matni, N., Recht, B., and Tu, S., "On the sample complexity of the linear quadratic regulator," Foundations of Computational Mathematics, pp. 1-47, 2017.

[23] Trong-Thang Nguyen, "The linear quadratic regular algorithm-based control system of the direct current motor," International Journal of Power Electronics and Drive Systems (IJPEDS), vol. 10, no. 2, pp. 768-776, 2019.

[24] Fossen, T. I., "Guidance and control of ocean vehicles," New York: Wiley, vol. 199, no. 4, 1994.

[25] Do, K. D., and Pan, J., "Control of ships and underwater vehicles: design for underactuated and nonlinear marine systems," Springer Science \& Business Media, 2009.

\section{BIOGRAPHIES OF AUTHORS}

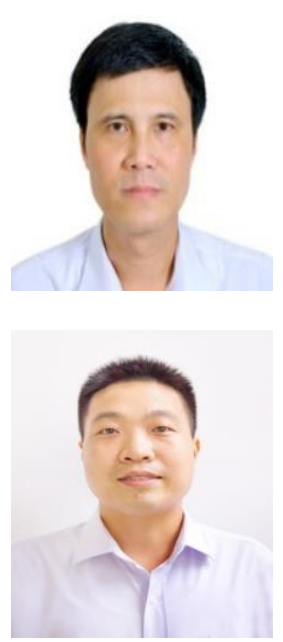

Manh-Cuong Nguyen was born in 1963, graduated (1987) in Vietnam Maritime University in Navigation, received the Master degree in Navigation Science in Vietnam Maritime University (2000), the Ph.D. degree in System Analysis, Control and Data Processing in Moscow Institute - Russia (2009). His main activity areas are Navigation, including Automation Control, Maritime Law, Maritime Safety and Security. He is a lecturer and then become Vice Dean of Faculty of Navigation (1988-2006). During this time he is working on board the vessels also and he was an experienced Captain of ocean-going vessels. At present, he is Dean of Faculty of Navigation under VMU.

Duc-Phuc Vuong received his B.S and M.S degrees in Marine Electrical Engineering and Automation from the Vietnam Maritime University in 2004 and 2007, respectively. He received his $\mathrm{PhD}$ degree in Electric and Control Engineering from the Mokpo National Maritime University, Korea, in 2014. He is currently a Dean of Marine Electric Division, Faculty of Electrical and Electronic Engineering of Vietnam Maritime University. His research interests are control of industrial machines, Robot control, LabVIEW software, recycle energy. 